\title{
Ad libitum milk replacer feeding, but not butyrate supplementation, affects growth performance as well as metabolic and endocrine traits in Holstein calves
}

\author{
D. Frieten, ${ }^{*}$ C. Gerbert,† C. Koch,† G. Dusel, ${ }^{*}$ K. Eder,‡ E. Kanitz,§ J. M. Weitzel,\# and H. M. Hammon $I^{1}$ \\ *Department of Life Sciences and Engineering, University of Applied Sciences Bingen, 55411 Bingen am Rhein, Germany \\ †Educational and Research Centre for Animal Husbandry, Hofgut Neumuehle, 67728 Münchweiler an der Alsenz, Germany \\ łInstitute of Animal Nutrition and Nutrition Physiology, Justus-Liebig-University Giessen, 35392 Giessen, Germany \\ §Institute of Behavioural Physiology, \\ \#Institute of Reproductive Biology, and \\ IIInstitute of Nutritional Physiology "Oskar Kellner," Leibniz Institute for Farm Animal Biology (FBN), 18196 Dummerstorf, Germany
}

\begin{abstract}
The enhanced growth performance of calves fed a higher plane of nutrition pre-weaning is well documented, and the effect of butyrate on the development of the gastrointestinal tract in calves has been evaluated. The aim of this study was to examine the synergistic effects of ad libitum milk replacer (MR) feeding and butyrate supplementation on growth performance and energy metabolism in calves. Sixty-four (32 male, 32 female) Holstein calves were examined from birth until wk 11 of life. Calves received MR either ad libitum (Adl) or restrictively (Res) with (AdlB,$+ \operatorname{ResB}+$ ) or without (AdlB-, ResB-) $0.24 \%$ butyrate supplementation. Colostrum and transition milk were fed in predefined amounts (Res or Adl) for the first $3 \mathrm{~d}$ postpartum. Ad libitum and restrictive MR feeding with or without butyrate was performed from d 4 until wk 8 of age. From wk 9 to 10, all calves were gradually weaned and were fed $2 \mathrm{~L} / \mathrm{d}$ until the end of the trial. Concentrate (CON), hay, and water were freely available. Intakes of MR and $\mathrm{CON}$ were measured daily. Calves were weighed at birth and weekly thereafter. Blood was drawn on d 1 before the first colostrum intake; on $\mathrm{d} 2,4$, and 7; and weekly thereafter until the end of the study to measure plasma concentrations of metabolites and hormones. Liver samples were taken at d 50 and at the end of the study to determine gene expression related to glucose metabolism. Milk, MR, and total nutrient intake were greater, but CON intake was lower in Adl than in Res calves, resulting in a greater body weight, but partially lower gain to feed ratio in Adl than in Res. Plasma concentrations of glucose and insulin were higher during the ad libitum milk-feeding period, whereas plasma
\end{abstract}

Received February 13, 2017.

Accepted April 11, 2017.

${ }^{1}$ Corresponding author: hammon@fbn-dummerstorf.de $\beta$-hydroxybutyrate was lower in Adl than in Res. Plasma concentrations of nonesterified fatty acids, lactate, total bilirubin, and cortisol were lower, but triglyceride and cholesterol concentrations were higher in Adl than in Res at specific time points. Feed intake, growth performance, and metabolic and endocrine changes were insignificantly affected by butyrate, and hepatic gene expression of enzymes related to endogenous glucose production was barely influenced by ad libitum MR feeding and butyrate supplementation. Intensive MR feeding indicated greater stimulation of growth and anabolic metabolism, but butyrate supplementation did not further improve postnatal growth or anabolic processes either in intensive or restrictive MR-fed calves. Key words: preruminant, ad libitum feeding, butyrate, glucose

\section{INTRODUCTION}

Several studies in pre-weaning calves have indicated improved development and body growth with the application of intensive milk feeding programs (Hammon et al., 2002; Schäff et al., 2016; Korst et al., 2017). This improved growth and development might have longlasting consequences on individual dairy performance (Bar-Peled et al., 1997; Bach, 2012; Van Amburgh and Soberon, 2013); however, the discussion on the extent of the milk feeding level is still ongoing, and restricted milk feeding to less than $6 \mathrm{~L} / \mathrm{d}$ is still common (Hill et al., 2016). Growing evidence suggests that insufficient liquid supply during the first weeks of postnatal life, fed either as milk or milk replacer (MR), compromises postnatal maturation and the health of calves and deviates significantly from the natural situation, as observed in beef calves (Schiessler et al., 2002; Khan et al., 2011, 2016). Intensive milk or MR feeding programs resulted in elevated DM and energy intake and body growth (Hammon et al., 2002; Jasper and Weary, 
2002) and accelerated organ development (Daniels et al., 2009; Geiger et al., 2016) during the pre-weaning period. Metabolic and endocrine changes in blood plasma pointed toward enhanced anabolic metabolism (Bartlett et al., 2006; Maccari et al., 2015; Schäff et al., 2016). In addition, it has been suggested that calves with elevated milk or MR intake during the pre-weaning period are less susceptible to illness (Ollivett et al., 2012; de Passillé et al., 2016). However, intensive milk feeding programs often last for only a few weeks after birth, supply milk or MR only twice daily (Bartlett et al., 2006; Daniels et al., 2008; Davis Rincker et al., 2011), and do not correspond to the ad libitum milk intake observed in beef calves (Egli and Blum, 1998; Schiessler et al., 2002).

Butyrate is known as a natural growth-stimulating substrate that enhances growth performance in young mammals (Guilloteau et al., 2010). In pre-weaning calves, butyrate supplementation in MR increases BW, structural growth, and health and affects insulin-dependent glucose metabolism (Górka et al., 2011; Kato et al., 2011). Butyrate deploys its stimulating effects on postnatal growth in young calves by accelerating postnatal maturation of the gastrointestinal tract and improving gut function (Guilloteau et al., 2009; Górka et al., 2014). The aim of the current study was to investigate feed intake, growth performance, and metabolic and endocrine changes in calves fed MR ad libitum supplemented with butyrate for $8 \mathrm{wk}$. We intended to combine the positive effects of intensive MR feeding and MR butyrate supplementation to test the hypothesis that both treatments stimulate postnatal growth and affect energy metabolism in calves related to anabolic processes in an additive manner. The dose for butyrate supplementation in MR was adapted from the work of Guilloteau et al. (2009) and Górka et al. (2011).

\section{MATERIALS AND METHODS}

The animal experiment was conducted from June 2014 to June 2015 at the Educational and Research Centre for Animal Husbandry, Hofgut Neumuehle, Germany. The experimental procedures in this study were performed in strict accordance with the German Animal Welfare Act and were approved by the relevant Department for Animal Welfare Affairs [Landesuntersuchungsamt Rheinland-Pfalz, Koblenz, Germany; registration no. 23 177-07/G 13-20-069)].

\section{Animals and Husbandry}

Sixty-four German Holstein calves $[\mathrm{n}=32$ each for intact male (not castrated) and female] were used from birth until $80 \pm 2$ (mean \pm SD) days of life. We used a birth monitoring system (iVET, Papenburg, Germany) to observe calving and to ensure that first blood sampling occurred before initial colostrum intake. The calves selected for this study met the following criteria: birth without assistance or with minor assistance (eutocia), pedigreed singletons, birth weight between 35 to $55 \mathrm{~kg}$, and physiological health and vigor. After colostrum intake, all calves received $10 \mathrm{~mL}$ of an iron paste $(115 \mathrm{mg}$ of $\mathrm{Fe} 3+/ \mathrm{mL}$ and $108 \mathrm{mg}$ of dextran/ $\mathrm{mL}$, Sinta GmbH, Schwarzenborn, Germany) and were treated for navel disinfection with an iodine solution (Albrecht GmbH, Aulendorf, Germany). Within 2 to $3 \mathrm{~h}$ after birth, the calves were brought to individual straw-bedded calf hutches. This husbandry lasted for $10 \pm 3 \mathrm{~d}$ (mean $\pm \mathrm{SD}$ ) before the calves were finally housed in an open straw-bedded stable. Calves that received no butyrate (ResB-, AdlB-) or butyrate supplementation (ResB+, AdlB+) were housed in opposite group pens and fed from 2 different automatic feeders. In each pen, 2 different feeding stations per feeder were available for calves younger than $3 \mathrm{wk}$ of age and calves 4 wk of age and older. The health of the calves was evaluated by daily rectal temperature measurement and navel and feces examination until wk 3 of age. Health maladies such as diarrhea, pneumonia, and navel illness were documented and treated by a veterinarian according to diagnosis. Clinical data from this portion of the study will be presented in a companion paper.

\section{Feeding and Diets}

Within $2 \mathrm{~h}$ after birth, all calves received $2.5 \pm 0.09 \mathrm{~kg}$ (mean $\pm \mathrm{SD}$ ) of colostrum from their dams via bottle. Because colostrum from their dams was not available, 5 calves received the same amount of colostrum from a high-quality colostrum reserve stored at $-20^{\circ} \mathrm{C}$, and quality was measured by specific gravity and optical Brix refractometers (Gross et al., 2016). Subsequently, the calves were allocated to 1 of the 4 feeding groups with respect to their sex, birth weight, and cow parity to create equal groups. For the following 5 meals (until d 3 of life), calves were fed acidified transition milk (2 $\mathrm{mL}$ of acidifier/L of milk, H. W. Schaumann GmbH, Pinneberg, Germany) from their dams with teat buckets either in amounts of $3 \mathrm{~L}$ per meal (Res; $\mathrm{n}=32$ ) or ad libitum (Adl; $\mathrm{n}=32$ ). From d 4 on, all calves were fed MR (12.5\% solids; Trouw Nutrition Deutschland GmbH, Burgheim, Germany) without supplementation or supplemented with calcium-sodium butyrate $(0.24 \%$ butyrate as fed; Benelux GmbH, Amel, Belgium) in amounts of either $6 \mathrm{~L} / \mathrm{d}$ (ResB-; ResB+; $\mathrm{n}=16$, re- 
spectively) or ad libitum (maximum $25 \mathrm{~L} / \mathrm{d}$; AdlB-; AdlB $+; \mathrm{n}=16$, respectively). The ingredients and the chemical composition of the MR are given in Table 1. The MR was stepped down linearly from d 57 to 70 in all groups and was fed in amounts of $2 \mathrm{~L} / \mathrm{d}$ until the end of the trial. During the first days of life, the feeding took place twice per day at 0700 and $1700 \mathrm{~h}$ in the hutches. Between feeding times, buckets for Adl calves were maintained with the calves and were refilled at noon if necessary. Teat buckets were covered with a lid to ensure that no rain or dirt contaminated the milk. In the stable, feeding was conducted using automatic feeding systems for MR and concentrate (Förster-Technik GmbH, Engen, Germany). Milk replacer was fed in small portions of a maximum of $2 \mathrm{~L}$ per meal for Res calves and a maximum of $5 \mathrm{~L}$ per meal for Adl calves, followed by an off time of $2 \mathrm{~h}$ for Res calves and $30 \mathrm{~min}$ for Adl calves after the end of the meal. Water and hay were freely available, and concentrate (pelleted starter; Raiffeisen Waren-Zentrale Rhein-Main eG, Köln, Germany; Table 1) was offered ad libitum in the stable.

\section{Measurement of Feed Intake, Feed Analyses, and BW}

During the period in the calf hutches, the daily milk and MR intakes were documented by weighing residues with an electronic scale (Sartorius AG, Göttingen, Germany). When calves were fed with the automatic feeding system, data for MR and concentrate intake were sent automatically to the connected PC program (Förster-Technik GmbH).

The nutrient compositions of the MR and concentrate were analyzed by an accredited external laboratory (Landwirtschaftliche Untersuchungs-und Forschungsanstalt, Speyer, Germany) according to the Weender standard procedure (Naumann and Bassler, 2004). Analyses of feedstuff were used to determine the ME content of concentrate according to GfE (2009). The composition of DM and energy from individual colostrum milkings was calculated using measurements from Kühne et al. (2000). The energy content of MR was calculated as gross energy on energy equivalents of $24.2,36.6$, and $17.0 \mathrm{MJ} / \mathrm{kg} \mathrm{DM}$ for $\mathrm{CP}$, crude fat, and total sugar, respectively. Gross energy for colostrum and $\mathrm{MR}$ was transformed into $\mathrm{ME}$ by $\mathrm{ME}=0.97 \times$ $0.96 \times$ gross energy (NRC, 2001).

The birth weight was measured after the first colostrum intake. The exact amount of ingested colostrum was subtracted from the initial weight. Body weight was recorded weekly until the end of the trial using a mobile scale (Tru-Test Ltd., Auckland, New Zealand). The ADG was calculated from BW with the precise number of days between weighing.
Table 1. Nutrient and chemical composition of the milk replacer (MR) and concentrate (CON)

\begin{tabular}{lcc}
\hline Item, \% of DM unless noted otherwise & $\mathrm{MR}^{1}$ & $\mathrm{CON}^{1}$ \\
\hline $\mathrm{DM}, \mathrm{g} / \mathrm{kg}$ & 968 & 866 \\
$\mathrm{CP}$ & 21.7 & 21.0 \\
Crude fat & 18.6 & 4.2 \\
Crude fiber & 0.2 & 5.9 \\
$\mathrm{ADF}_{\mathrm{OM}^{2}}$ & $\mathrm{ND}^{3}$ & 8.1 \\
$\mathrm{NDF}_{\mathrm{OM}}$ & $\mathrm{ND}$ & 16.5 \\
Ash $^{4}$ & 7.3 & 7.0 \\
$\mathrm{NFE}^{4}$ & 52.1 & 61.9 \\
Total sugar & 44.9 & $\mathrm{ND}$ \\
$\mathrm{ME},{ }^{5} \mathrm{MJ} / \mathrm{kg}$ of DM & 18.34 & 13.15 \\
$\mathrm{Ca}$ & 1.17 & 1.22 \\
$\mathrm{P}$ & 0.65 & 0.66 \\
Na & 0.47 & 0.29 \\
$\mathrm{~K}$ & 1.43 & 1.21 \\
Lysine & 1.8 & $\mathrm{ND}$ \\
Methionine & 0.48 & $\mathrm{ND}$ \\
\hline
\end{tabular}

${ }^{1}$ Ingredients of MR: $50 \%$ skim milk powder, $25 \%$ whey powder, $16.5 \%$ vegetable oil, $3 \%$ wheat powder; MR fed to butyrate-supplemented restrictive (ResB+) and ad libitum (AdlB + ) treatments contained $0.24 \%$ butyrate of DM. Ingredients of CON: $35.0 \%$ corn, $23.0 \%$ soybean meal, $13.0 \%$ beet pulp dried with molasses, $7.5 \%$ wheat, $6.0 \%$ barley, $3.2 \%$ rapeseed meal, $3.0 \%$ linseed meal, $3.0 \%$ beet pulp, $2.0 \%$ wheat bran, $0.09 \%$ calcium carbonate, and $0.05 \%$ mono-calcium phosphate.

${ }^{2}$ Acid detergent fiber and NDF are expressed exclusive of residual ash. The NDF was assayed with a heat-stable amylase (Korst et al., 2017). ${ }^{3} \mathrm{ND}=$ not determined.

${ }^{4}$ Nitrogen-free extract (NFE), calculated as NFE $=100-(\mathrm{CP}+$ crude fat + crude fiber + ash).

${ }^{5} \mathrm{ME}$ calculated using the equation: $\mathrm{ME}, \mathrm{MJ} / \mathrm{kg}$ of $\mathrm{DM}=(24.2 \times \mathrm{CP}$ $+36.6 \times$ fat $+17.0 \times$ total sugar $) / 100 \times 0.97 \times 0.96$.

\section{Blood and Liver Sampling and Analyses}

Blood samples were collected from a jugular vein before first colostrum intake (d 1), $24 \mathrm{~h}$ after colostrum intake (d 2), before first MR intake (d 4), and subsequently on d $7,14,21,28,35,42,49,56,63,70$, and 77. Ad libitum milk-fed calves were fasted for at least $1 \mathrm{~h}$ before blood sampling. Blood from Res calves was drawn before the morning feeding in the calf hutches or after $1 \mathrm{~h}$ fasting in group pens. After shaving and disinfecting the skin, the vein was punctured and blood was collected in evacuated tubes (Greiner Bio-One GmbH, Frickenhausen, Germany) containing potassium-EDTA $(1.8 \mathrm{mg} / \mathrm{mL})$ and tubes containing sodium fluoride $(2-4$ $\mathrm{mg} / \mathrm{mL}$ ) and potassium oxalate $(1-3 \mathrm{mg} / \mathrm{mL})$. Blood samples were held on ice until centrifugation at 3,500 $\times g$ for 10 min at room temperature. The supernatants from plasma were pipetted into aliquots and stored at $-20^{\circ} \mathrm{C}$ until analyzed.

Analyses of metabolites [glucose, BHB, lactate, urea, nonesterified fatty acids (NEFA), triglyceride, cholesterol, and total bilirubin] were performed from sodium fluoride/potassium oxalate plasma. Insulin, glucagon, and cortisol concentrations were determined from EDTA plasma. All metabolites were analyzed spectrophoto- 
metrically (HORIBA ABX SAS, Montpellier, France). The following kits were used: glucose (\#A11A01667), lactate (\#A11A01721), and triglyceride (\#A11A01640; Axon Lab AG, Baden, Switzerland); BHB (\#RB1008), urea (\#LT-UR 0010), and total bilirubin (\#LT-BR 0500, LABOR + TECHNIK Eberhard Lehmann GmbH, Berlin, Germany); NEFA (\#434-91795, Wako Chemicals GmbH, Neuss, Germany); and cholesterol (\#553-127, mti diagnostics GmbH, Idstein, Germany). Butyrate analysis in blood plasma was performed as recently described (Laeger et al., 2012).

Plasma concentrations of insulin (\#RIA-1257) and glucagon (\#RIA-1258) were determined by RIA using kits from DRG Instruments GmbH (Marburg, Germany), which were adapted to bovine subjects (Hammon et al., 2009). Intra- and interassay coefficients of variation were 3.7 and $5.5 \%$ for insulin and 3.4 and $22.5 \%$ for glucagon, respectively. The plasma cortisol concentration was analyzed in duplicate after extraction with diethylether using a commercially available ELISA kit (\#EIA1887, DRG Instruments GmbH; Gruse et al., 2016). The assay was validated for the use with bovine plasma. The test sensitivity was $3.4 \mu \mathrm{g} / \mathrm{L}$, and the intra- and interassay coefficients of variation were 5.3 and $12.1 \%$, respectively.

On d $50 \pm 2$ and d $80 \pm 2$ (mean $\pm \mathrm{SD}$; d 80 females only), approximately 80 to $100 \mathrm{mg}$ of liver tissue was collected from each calf by biopsy (modified from Swanson et al., 2000) with a Bard Magnum biopsy instrument and Bard Magnum core tissue biopsy needle (C.R. Bard Inc., Covington, GA). Liver samples of male calves on d $80 \pm 2($ mean $\pm \mathrm{SD})$ were collected after calves were harvested at the end of the study. Liver samples were flushed in ice-cold $0.9 \% \mathrm{NaCl}$ and frozen in liquid nitrogen. For further analysis, the liver tissue was pulverized in liquid nitrogen. Glycogen content was determined with the use of a commercial kit based on amyloglucosidase-catalyzed glucose release (no. 10207748035; Roche Diagnostics GmbH, Mannheim, Germany). The relative mRNA abundance of genes related to glucose metabolism was quantified as previously described (Saremi et al., 2012; Schäff et al., 2016). Primer sequences and PCR conditions for reference genes [hippocalcin-like 1 (HPCAL1), low-density lipoprotein 10 (LRP10), and RNA polymerase II (POLR2A)] and target genes [glycogen phosphorylase $(P Y G L)$, glucose-6-phosphatase $(G 6 P C)$; phosphoenolpyruvate carboxykinase (cytosolic: PCK1; mitochondrial: PCK2), pyruvate carboxylase $(P C)$, and propionyl-CoA carboxylase $\alpha$ $(P C C A)]$ were recently published (Saremi et al., 2012; Gruse et al., 2015; Schäff et al., 2016). The primer products were verified by sequencing applied with the BigDye Terminator v1.1 Cycle Sequencing kit and an ABI 3130 Genetic Analyzer (Thermo Fisher Scientific
Inc., Waltham, MA). Real-time PCR was performed with the use of a LightCycler (F. Hoffmann-La Roche AG, Basel, Switzerland). The fluorescent dye used was SYBR Green I. Melting curve analysis and agarose gel electrophoresis were used to confirm the specificity of the PCR products. Quantification cycle values and amplification efficiencies obtained with the use of LinRegPCR version 2013.0 (Ruijter et al., 2013) were imported into qBASE+ version 2.6.1 (Biogazelle NV, Zwijnaarde, Belgium) for all subsequent calculations and quality controls (Gruse et al., 2015; Schäff et al., 2016). The geometric mean of the reference gene abundances was applied for normalization. The data are presented as the ratio of the copy number of the respective gene of interest to the geometric mean of the reference gene abundance.

\section{Statistical Analyses}

Data were evaluated by repeated-measures ANOVA using PROC MIXED in SAS for Windows (release 9.4, SAS Institute Inc., Cary, NC). The ANOVA model contained the fixed effects of feeding regimen (Res vs. Adl), butyrate supplementation, time, sex, and respective interactions. Repeated measures on each calf were considered using the repeated statement of the MIXED procedure using an unstructured type of block diagonal residual covariance matrix structure (SAS Institute Inc.). Least squares means and their standard errors were computed for each fixed effect in the models, and all pair-wise differences of least squares means were tested with the Tukey-Kramer procedure. The SLICE statement of the MIXED procedure was used to conduct partitioned analyses of the least squares means for interactions. Differences in data with $P$-values $<0.05$ were defined as significant, and $P$-values $<0.1$ were considered as trends. Values are presented as least squares means \pm standard error if not declared otherwise in the text.

\section{RESULTS}

\section{Feed Intake and Growth Performance}

Intake of first colostrum (first milking) was similar for all calves $(2.5 \pm 0.01 \mathrm{~L}, \mathrm{LSM} \pm \mathrm{SE})$. However, during the subsequent 5 meals, Adl calves consumed $25.4 \%$ more transition milk than Res calves. Sum of first colostrum and transition milk intakes for all $3 \mathrm{~d}$ were $19.8 \pm 0.5 \mathrm{~L}$ for $\mathrm{Adl}$ and $14.8 \pm 0.5 \mathrm{~L}$ for Res. Furthermore, MR intake, and hence $\mathrm{ME}, \mathrm{CP}$, and fat intake, were higher $(P<0.01)$ from wk 1 to 10 in Adl than in limited milk-fed calves (Figure 1A; Table 2). The DMI of milk powder reached the highest amount 
of $1.7 \mathrm{~kg} / \mathrm{d}$ in wk 5 for AdlB - and in wk 8 for AdlB+. These amounts were 2.3 times greater than the intake of the respective Res groups. Butyrate supplementation did not affect MR intake in a significant manner throughout the study, but butyrate-fed calves showed a trend $(P=0.09)$ of lower MR intake in wk 1 . The concentrate intake, as shown in Figure 1B, was negligible for all calves in the first $3 \mathrm{wk}$ of life. The concentrate intake increased, as did ME, CP, and fat intake of the concentrate, at the age of $4 \mathrm{wk}$ in the Res groups, and the increase occurred earlier than for the Adl groups, resulting in a greater $(P<0.01)$ concentrate intake in Res than in Adl calves from wk 4 on throughout the study. In wk 5 , concentrate intake was higher $(P$ $=0.03$ ) for butyrate-fed groups, but no other effects of butyrate supplement on concentrate intake were observed. The total DMI and ME, CP, and fat intake were greater $(P<0.01)$ in Adl than in Res calves (Table 2$)$. The ME intake by MR compared with concentrate was greater until wk 8 of age for Res groups and until wk 10 of age for Adl groups. At wk 11, 89, 85, 88, and $86 \%$ of ME came from concentrate intake for ResB-, AdlB-, ResB+, and AdlB+, respectively.

Birth weights ranged from 36.5 to $53.5 \mathrm{~kg}$. For our groupings, the mean birth weight $(43.6 \pm 0.6 \mathrm{~kg})$ did not differ among the groups. The BW was greater $(P$ $<0.01)$ in Adl than in Res groups for the entire trial (Figure 2A). Butyrate supplement resulted in a trend of lower BW in wk $5(P=0.11)$ and $6(P=0.1)$ and from wk 9 until the end of the study $(P<0.1)$. The ADG was approximately 1.8 times greater $(P<0.01)$ in Adl than in Res groups until wk 6 of age, greatest in wk $9(P<0.01)$ in AdlB-, but greater $(P<0.01)$ in wk 10 and 11 in Res than in Adl calves (Figure 2B). The ADG over the total experimental period was greater $(P$ $<0.01)$ in Adl than in Res calves $(980 \pm 22$ and $795 \pm$ $22 \mathrm{~g} / \mathrm{d}$ for Adl and Res calves, respectively). The gain to feed ratio changed with time and was higher in wk 1 $(P=0.01)$ but lower $(P<0.01)$ in wk $5,7,8$, and 10 in Adl than in Res calves and was reduced $(P<0.01)$ by butyrate in wk 9 (Figure 2C).

\section{Metabolic Profiles}

The results of selected metabolites that reflect carbohydrate metabolism and urea are presented in Figure 3. The concentration of butyrate in blood plasma was below the detection limit in all calves (data not shown). The glucose concentration in blood plasma increased $(P<0.01)$ in all groups after first feed intake and was higher $(P<0.01)$ until d 56 but lower $(P<0.01)$ on d 70 and 77 in Adl than in Res calves (Figure 3A). Butyrate supplementation decreased plasma glucose on d 14, 21, and $42(P<0.05)$. Plasma glucose tended to be greater $(P<0.06)$ in female than in male calves (data not shown). Plasma BHB concentration was lower $(P<0.05)$ on $\mathrm{d} 4$ but was higher $(P<0.01)$ on d 7 in Res than in Adl calves (Figure 3B). The plasma concentration of BHB increased from d 35 on in Res calves and was higher $(P<0.01)$ from d 35 to 70 in Res than in Adl calves. In Adl calves, the increase in plasma BHB concentration was delayed starting on $\mathrm{d}$ 70. Plasma lactate concentration decreased $(P<0.01)$ from birth to the end of the first month of age in all groups and was higher $(P<0.01)$ on $\mathrm{d} 4,7$, and 70 but lower $(P<0.05)$ on d 28 in Res than in Adl calves (Figure 3C). Plasma urea concentration increased $(P<$ 0.01 ) from d 2 to 4 in Adl calves but showed the lowest concentration in all groups on d 7 (Figure 3D). Urea

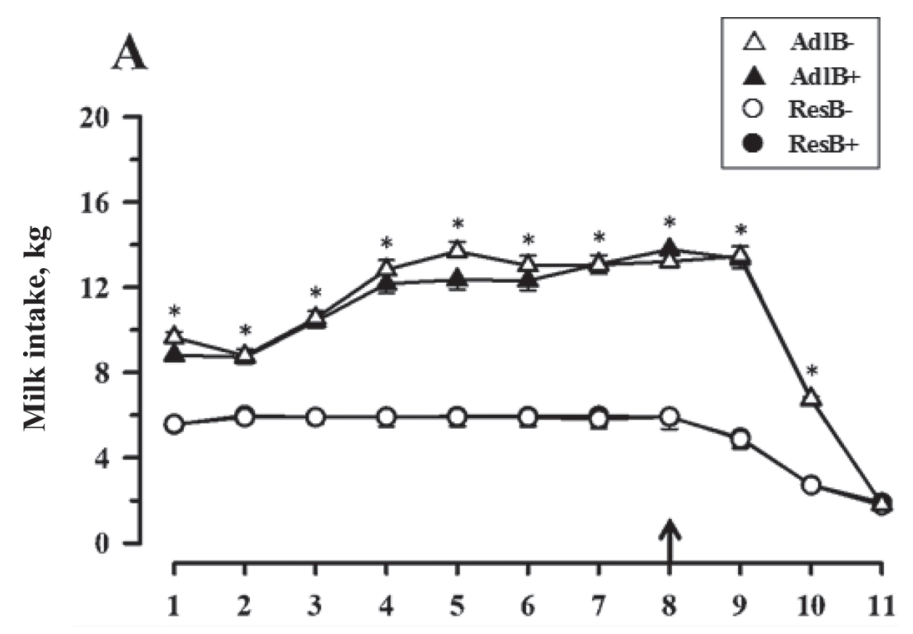

B

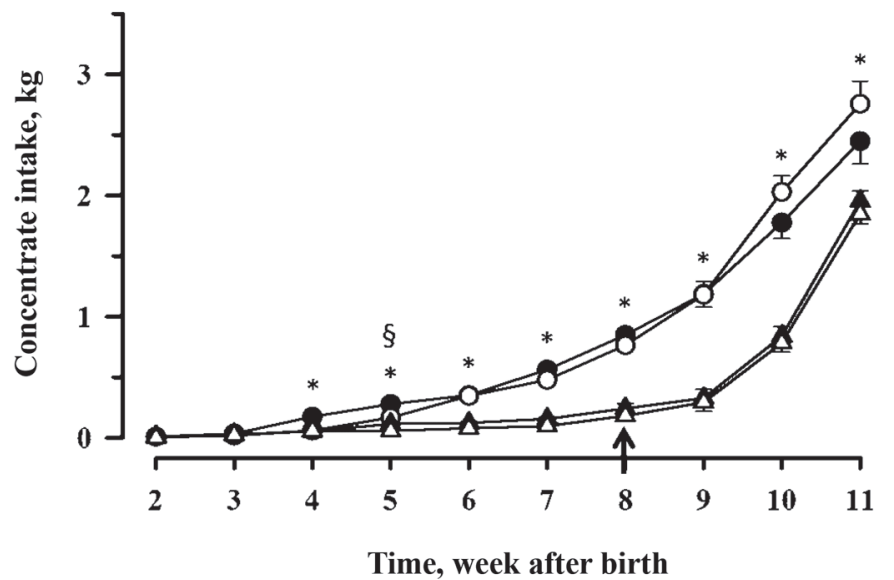

Figure 1. Milk and milk replacer (MR; A) and concentrate (B) intake in calves fed milk and MR either ad libitum or restrictively and supplemented MR without ( $\Delta$ AdlB-; $\bigcirc$ ResB-) or with $0.24 \%$ butyrate $(\boldsymbol{A} \mathrm{AdlB}+; \bullet \operatorname{ResB}+)$. Arrow marks the start of weaning. Data are presented as weekly $\mathrm{LSM} \pm \mathrm{SE}$; * indicates the effect of feeding regimen $(P<0.05) ; \S$ indicates the effect of butyrate supplementation $(P<0.05)$. 
concentration was higher $(P<0.01)$ on $\mathrm{d} 4$ but lower $(P=0.01)$ on $\mathrm{d} 28$ in Adl than in Res calves.

Figure 4 presents data from fat metabolism. Plasma NEFA concentration decreased $(P<0.01)$ with time during the first $2 \mathrm{wk}$ and was lower $(P<0.01)$ on $\mathrm{d} 4$ and 21 but higher $(P<0.01)$ on $\mathrm{d} 70$ in Adl than in Res calves (Figure 4A). Plasma triglyceride concentration increased $(P<0.01)$ in all groups from d 1 to 4 and increased $(P<0.01)$ again in Adl calves on d 21 (Figure 4B). Triglyceride concentration was higher on d 21 but lower on d 70 in Adl than in Res calves. The triglyceride concentration before first colostrum intake was higher in calves that were later supplemented with butyrate. Plasma cholesterol concentration increased $(P<0.01)$ up to wk 4 of life in all groups (Figure $4 \mathrm{C})$, remained constant for $5 \mathrm{wk}$ in Res and for $6 \mathrm{wk}$ in Adl calves, and subsequently decreased to the end of the study in all groups. The Adl calves had a higher cholesterol concentration $(P<0.05)$ than Res calves on d 28, 70, and 77. Plasma total bilirubin concentration increased in all calves after colostrum intake on $\mathrm{d}$ 2 and decreased until the end of the trial $(P<0.01$; Figure 4D). The Res calves showed a slower decrease than Adl calves from d 2 to $14(P<0.01)$, and ResB+ calves had the highest concentrations on $\mathrm{d} 1,4,7$, and 21 , resulting in milk feeding effects on these days $(P$ $<0.01)$ and a butyrate effect $(P<0.05)$ on $\mathrm{d} 4$. Total bilirubin concentration was higher $(P<0.01)$ on d 70 in Adl than in Res calves.

\section{Hormone Profiles}

The plasma insulin concentration was higher $(P<$ 0.05 or less) from d 4 to 63 but lower $(P<0.01)$ on d
70 in Adl than in Res calves and was higher $(P<0.05)$ on d 28 in calves that were fed butyrate (Figure 5A). Plasma glucagon concentration increased $(P<0.01)$ after first colostrum intake in all groups, remained high in Adl calves, and decreased $(P<0.01)$ in Res calves on $\mathrm{d} 4$ and decreased $(P<0.01)$ in all groups to $\mathrm{d}$ 7 (Figure 5B). Glucagon concentration was higher $(P$ $<0.01)$ on d 4 in Adl than in Res calves. A trend of higher glucagon concentration in Res than in Adl calves $(P<0.1)$ was observed on d 28,35 , and 49 . Plasma concentrations of insulin and glucagon were greater $(P$ $<0.01$ ) in female than in male calves (data not shown). The plasma cortisol concentration decreased from birth until d 14 of life in all groups and remained stable thereafter (Figure 5C). The plasma cortisol concentration was lower $(P<0.01)$ in Adl than in Res calves from d 4 to 21 and on d 63 and 70 and was highest on d 77 in ResB+.

\section{Hepatic Glycogen Concentration and Gene Expression Related to Glucose Metabolism}

The hepatic glycogen concentration decreased $(P<$ $0.01)$ in all groups from d 50 to 80 and was greater $(P<0.01)$ in Adl than in Res calves, especially when butyrate was supplemented (Table 3 ). The glycogen concentration was greater $(P<0.05)$ in female than in male calves (data not shown). The mRNA abundance of $P Y G L$ and $G 6 P C$ increased $(P<0.01)$ with time and was greater $(P<0.05)$ in male than in female calves (data not shown). The mRNA abundance of $P C K 1$ and $P C K 2$ increased $(P<0.01)$ with time, and for PCK1, mRNA abundance on d 50 tended to be greater but on d 80 tended to be lower in $\mathrm{B}-$ than $\mathrm{B}+$ calves (time

Table 2. Dry matter, ME, CP, and fat intake of liquid, concentrate, and total feed (liquid and concentrate) intake of calves fed milk and milk replacer (MR) either ad libitum or restrictively and supplemented MR without (ResB-; AdlB-) or with 0.24\% butyrate (ResB+; AdlB+)

\begin{tabular}{|c|c|c|c|c|c|c|c|c|c|}
\hline Item $^{1}$ & \multicolumn{4}{|c|}{ Dietary treatment } & SEM & \multicolumn{4}{|c|}{ Fixed effect, $P$-value } \\
\hline $\mathrm{DM}, \mathrm{kg} / \mathrm{d}$ & 0.63 & 1.30 & 0.63 & 1.26 & 0.03 & $<0.001$ & 0.6 & $<0.001$ & 0.7 \\
\hline $\mathrm{ME}, \mathrm{MJ} / \mathrm{d}$ & 11.0 & 22.4 & 11.1 & 22.0 & 0.54 & $<0.001$ & 0.6 & $<0.001$ & 0.7 \\
\hline $\mathrm{CP}, \mathrm{g} / \mathrm{d}$ & 136 & 282 & 138 & 274 & 6.73 & $<0.001$ & 0.6 & $<0.001$ & 0.7 \\
\hline Crude fat, g/d & 117 & 242 & 118 & 235 & 5.77 & $<0.001$ & 0.6 & $<0.001$ & 0.7 \\
\hline $\mathrm{ME}, \mathrm{MJ} / \mathrm{d}$ & 8.78 & 3.89 & 8.84 & 4.55 & 0.65 & $<0.001$ & 0.6 & $<0.001$ & 0.3 \\
\hline $\mathrm{CP}, \mathrm{g} / \mathrm{d}$ & 140.2 & 62.1 & 141.0 & 72.6 & 10.39 & $<0.001$ & 0.6 & $<0.001$ & 0.3 \\
\hline Crude fat, g/d & 28.0 & 12.4 & 28.2 & 14.5 & 2.08 & $<0.001$ & 0.6 & $<0.001$ & 0.3 \\
\hline \multicolumn{10}{|l|}{ Total feed intake } \\
\hline $\mathrm{DM}, \mathrm{kg} / \mathrm{d}$ & 1.24 & 1.57 & 1.25 & 1.58 & 0.06 & $<0.001$ & 0.9 & $<0.001$ & 0.5 \\
\hline $\mathrm{ME}, \mathrm{MJ} / \mathrm{d}$ & 19.0 & 26.2 & 19.2 & 26.2 & 0.81 & $<0.001$ & 1.0 & $<0.001$ & 0.6 \\
\hline $\mathrm{CP}, \mathrm{g} / \mathrm{d}$ & 264 & 338 & 266 & 340 & 11.72 & $<0.001$ & 0.9 & $<0.001$ & 0.5 \\
\hline
\end{tabular}

\footnotetext{
${ }^{1}$ Values are presented as LSM for the whole experimental period.
} 


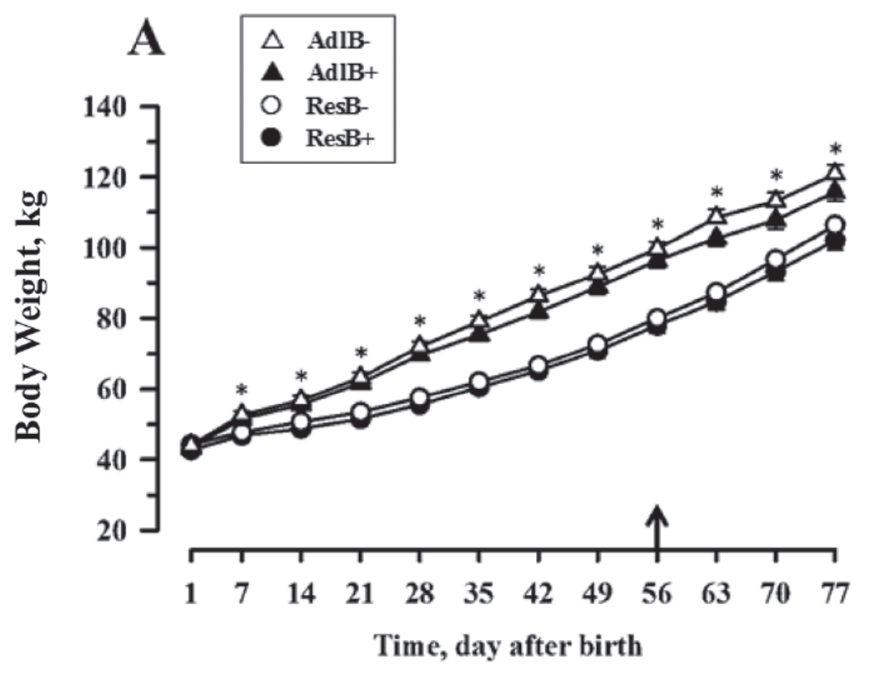

B

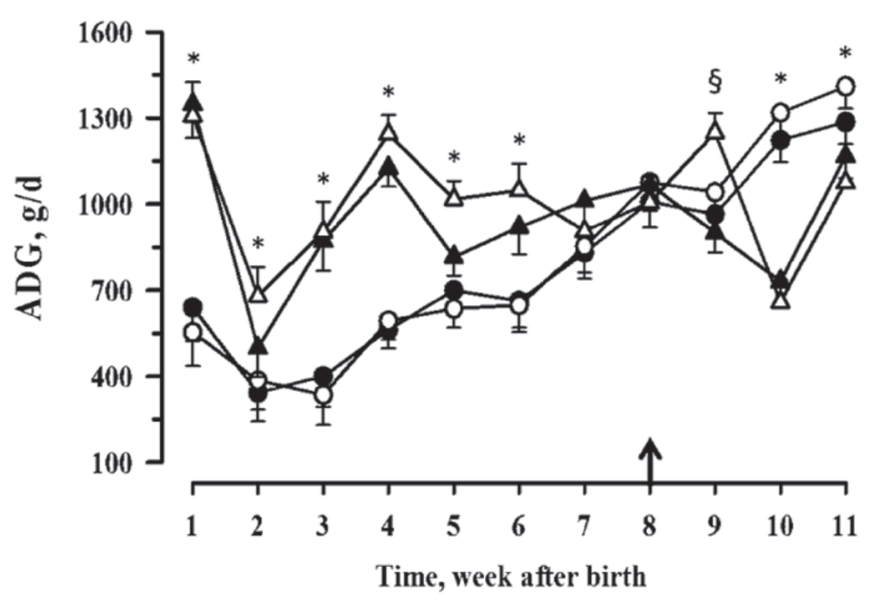

C



Figure 2. Body weight (A), ADG (B), and gain to feed ratio (C) in calves fed milk and milk replacer (MR) either ad libitum or restrictively and supplemented MR without ( $\Delta$ AdlB-; $\bigcirc$ ResB-) or with $0.24 \%$ butyrate $(\boldsymbol{\Delta}$ AdlB $+; \bullet$ ResB +$)$. Arrow marks the start of weaning. Data are presented as LSM $\pm \mathrm{SE}$; * indicates the effect of feeding regimen $(P<0.05) ; \S$ indicates the effect of butyrate supplementation $(P<0.05)$ $\times$ butyrate, $P=0.06)$. The mRNA abundance of $P C$ on $\mathrm{d} 80$ tended to be greater $(P=0.1)$ in $\mathrm{B}+$ than in $\mathrm{B}-$ calves. The mRNA abundance of $P C C A$ increased with time $(P<0.001)$, tended to be slightly lower $(P$ $<0.1)$ in $\mathrm{B}+$ than in $\mathrm{B}-$ calves on $\mathrm{d} 50$, and tended to be greater $(P<0.1)$ in Adl than in Res calves on $d 80$.

\section{DISCUSSION}

\section{Effects of Milk Feeding Intensity and Butyrate Supplementation on Feed Intake and Growth Performance}

Allowing calves to drink unlimited amounts of milk and MR during the pre-weaning period more than doubles liquid feed intake in Adl calves compared with that in Res calves, which supports previous findings (Hammon et al., 2002; Maccari et al., 2015; Schäff et al., 2016). The MR intake in ad libitum fed calves was greater than in common intensive milk-feeding programs for pre-weaning calves (Bartlett et al., 2006; Davis Rincker et al., 2011). However, the greater CP and fat content of the MR used in previous studies than that used in the present study might partially account for the higher protein and ME intake in intensive MRfeeding programs than that in the ad libitum MR feeding of the current study (Brown et al., 2005; Daniels et al., 2008; Geiger et al., 2016).

The overall concentrate intake was much lower in Adl than in Res calves. Even at the end of the study, Adl calves did not reach the concentrate intake measured in Res calves, although the increase in concentrate intake at the end of the study (i.e., when MR intake was reduced in all calves to $2 \mathrm{~L}$ ) was greater in Adl calves. This finding was a consequence of the long-lasting ad libitum MR feeding period in the current study. The Adl calves received unlimited amounts of MR up to wk 9 of age because the feeding program began reduction of MR intake from $25 \mathrm{~L} / \mathrm{d}$ in wk 8 . The MR reduction in wk 8 had no consequences for MR intake in most of the Adl calves because maximal MR intake was mostly 14 to $15 \mathrm{~L} / \mathrm{d}$. However, certain calves reached a milk intake of $25 \mathrm{~L} / \mathrm{d}$ for several days. Time for reduction of MR feeding in Adl calves was probably too short in our study. It is well known that too abrupt decrease of milk feeding in intensive milk-fed calves leads to depression of feed intake and growth during weaning (Khan et al., 2011). Previous studies with a shorter ad libitum milk-feeding period indicated no negative effect or even a greater concentrate intake after the ad libitum milk-feeding period in pre-weaning calves (Khan et al., 2011; Schäff et al., 2016; Korst et al., 2017). In calves fed milk at $20 \%$ of BW for the first $25 \mathrm{~d}$ of life, concentrate intake was greater after the intensive 
milk-feeding period than in calves fed milk at $10 \%$ of BW (Khan et al., 2007). Nevertheless, reduced solid feed intake during ad libitum or intensive milk feeding is a common phenomenon, illustrating the preference for milk or MR instead of concentrate in pre-weaning calves (Jasper and Weary, 2002; Davis Rincker et al., 2011; Miller-Cushon et al., 2013). However, at the end of the study, when MR intake was reduced to $2 \mathrm{~L}$ for all calves, the portion of ME intake delivered by the concentrate was comparable among all calves. This observation shows that Adl calves immediately switch to concentrate intake when MR is reduced. In addition, plasma concentration of $\mathrm{BHB}$, which is a result of concentrate digestion in the rumen, did not differ between Adl and Res calves at the end of the study.

Overall, total nutrient intake was much greater in Adl than in Res calves, and the nutrient intake was determined by the elevated MR intake in Adl calves, which supports previous studies (Khan et al., 2011, 2016). Total ME intake was $27 \%$ less and total CP and fat intake were 22 and $43 \%$ less in Res than in Adl calves, showing that the greater concentrate intake in Res calves could not compensate for the lower MR intake in these calves. The greater nutrient intake in Adl calves caused improved body growth and resulted in Adl calves that were $14 \mathrm{~kg}$ heavier at the end of the study. The ADG per week was greater until wk 6 of age but was lower at the end of the study (especially in wk 10) in Adl calves. Therefore, the elevated concentrate intake in Res calves led to comparable weekly ADG with age but could not compensate for the impaired body growth during the first weeks of age, which is consistent with previous studies (Khan et al., 2011, 2016; Schäff et al., 2016). The reduced ADG in wk 10 mirrored the lower feed intake in Adl calves during weaning because the reduction of MR intake during wk

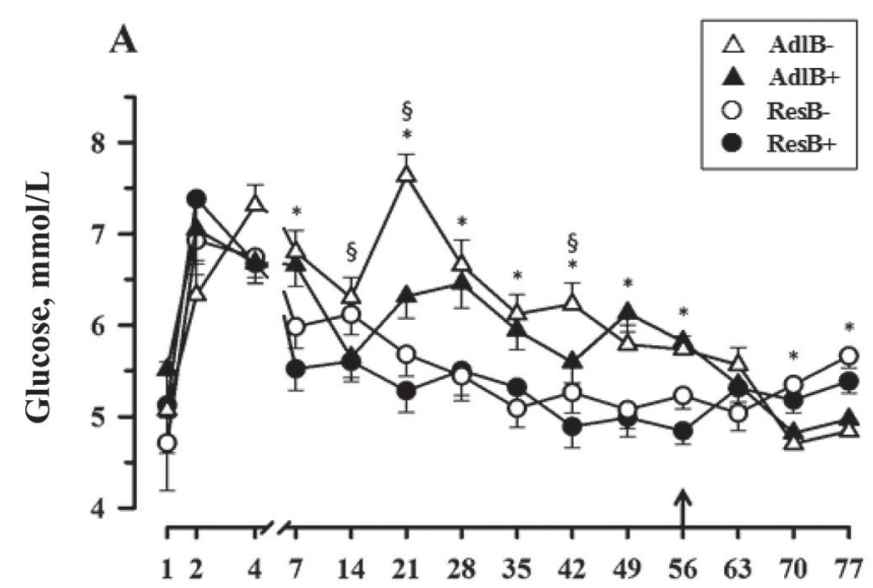

B

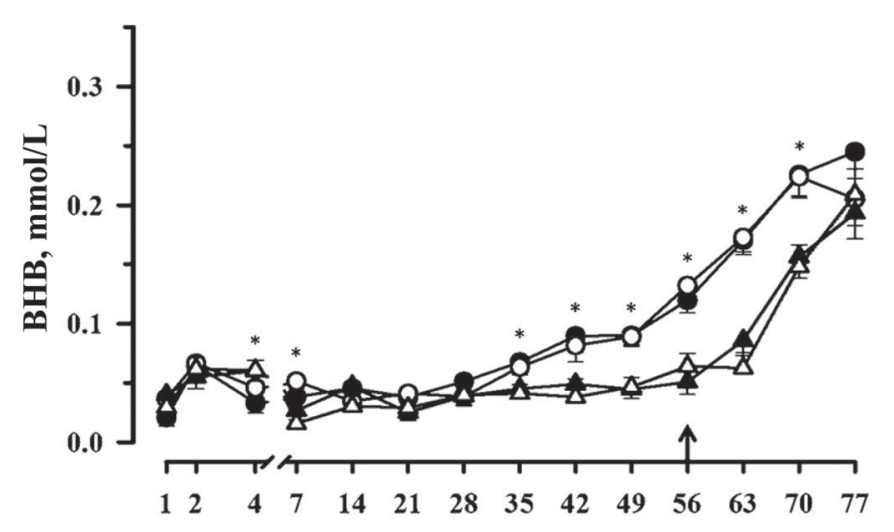

Time, day after birth

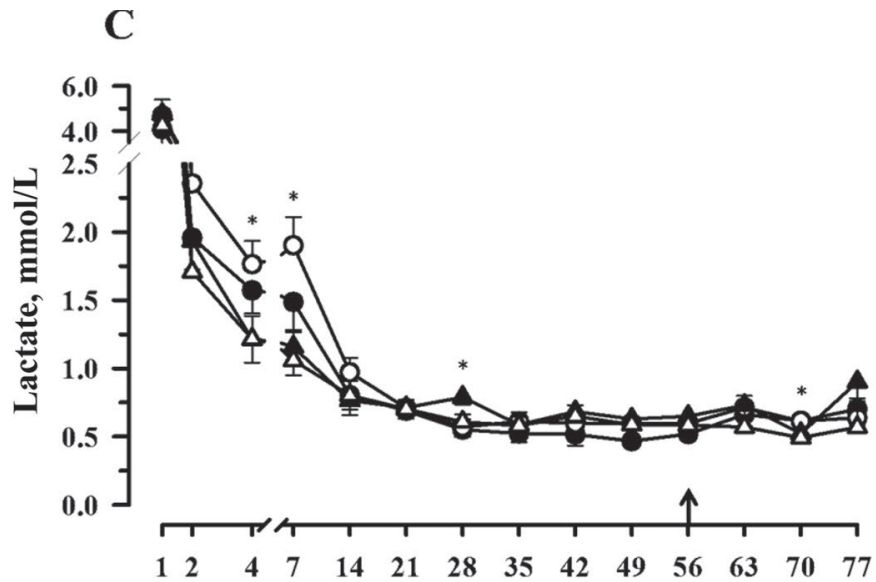

D

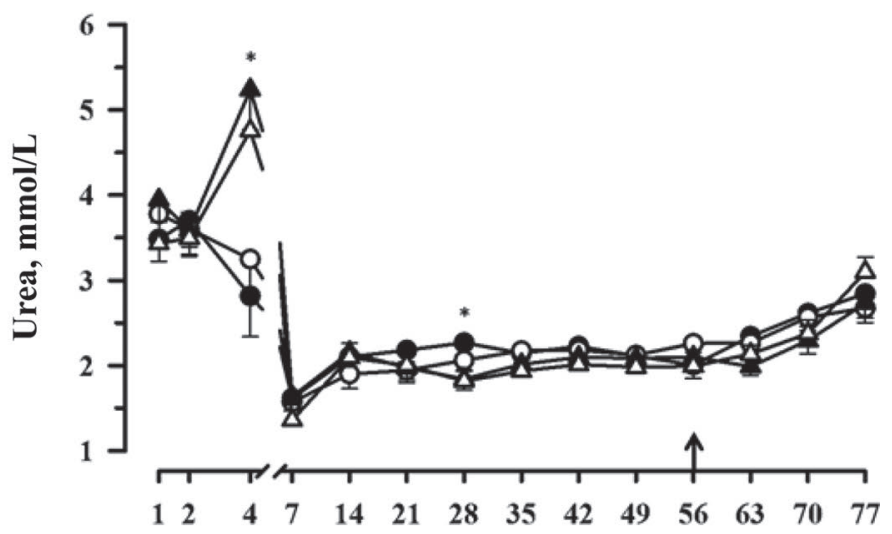

Time, day after birth

Figure 3. Blood plasma concentrations of glucose (A), BHB (B), lactate (C), and urea (D) in calves fed milk and milk replacer (MR) either ad libitum or restrictively and supplemented MR without ( $\Delta$ AdlB-; $\bigcirc$ ResB - ) or with $0.24 \%$ butyrate $(\boldsymbol{\Delta}$ AdlB + ; $\bullet$ ResB +$)$. Arrow marks the start of weaning. Data are presented as LSM $\pm \mathrm{SE} ; *$ indicates the effect of feeding regimen $(P<0.05) ; \S$ indicates the effect of butyrate supplementation $(P<0.05)$. 
10 was not compensated by the concentrate intake. A more gentle MR reduction in Adl calves could probably avoid such a drop in ADG in Adl calves. However, our findings indicate the greatest potential for stimulation of body growth via ad libitum milk feeding during the first 6 wk of age, which supports previous findings (Korst et al., 2017). Subsequently, an impaired gain to feed ratio in ad libitum milk-fed calves became obvious. This observation contrasts with previous studies in which intensive milk/MR feeding improved the feed efficiency in pre-weaning calves (Bartlett et al., 2006; Khan et al., 2007; Davis Rincker et al., 2011), but a reduced feed efficiency was recently also found in calves fed MR ad libitum for the first $5 \mathrm{wk}$ of age (Schäff et al., 2016). Obviously, the prolonged ad libitum milk feeding period in the current study compromises feed efficiency, but the calculated feed efficiency does not validate organ maturation and organ development, such as mammary gland development, in pre-weaning heifer calves (Geiger et al., 2016). In addition, the enhanced gain to feed ratio in Res calves from wk 7 of age on might partly be a result of greater solid feed intake in Res calves leading to enhanced gut filling.

Butyrate supplementation of MR insignificant affected feed intake and growth performance in the current study. At wk 5 of age, concentrate intake was slightly greater in calves fed butyrate, and a trend of slightly reduced growth was noted in both butyrate-fed groups. In addition, the gain to feed ratio was reduced by butyrate supplementation in wk 9 of age. These findings of the effect of butyrate supplementation in MR on feed intake and growth performance were not expected because, in previous studies, butyrate supplementation in MR with a comparable dose led to improved growth performance (Górka et al., 2011) and feed efficiency (Guilloteau et al., 2009, 2010). Reasons for these different findings are presently not obvious because butryrate dose in MR and MR feeding intensity were comparable

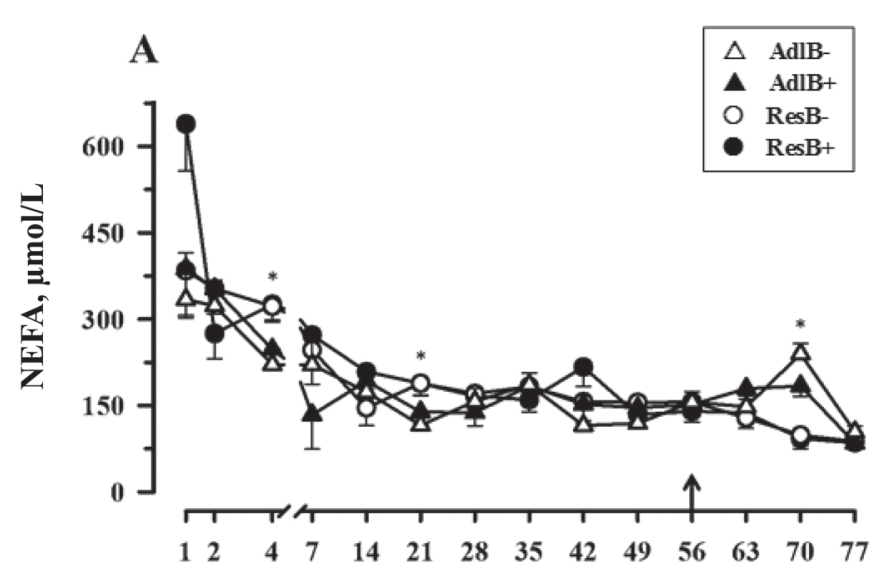

B

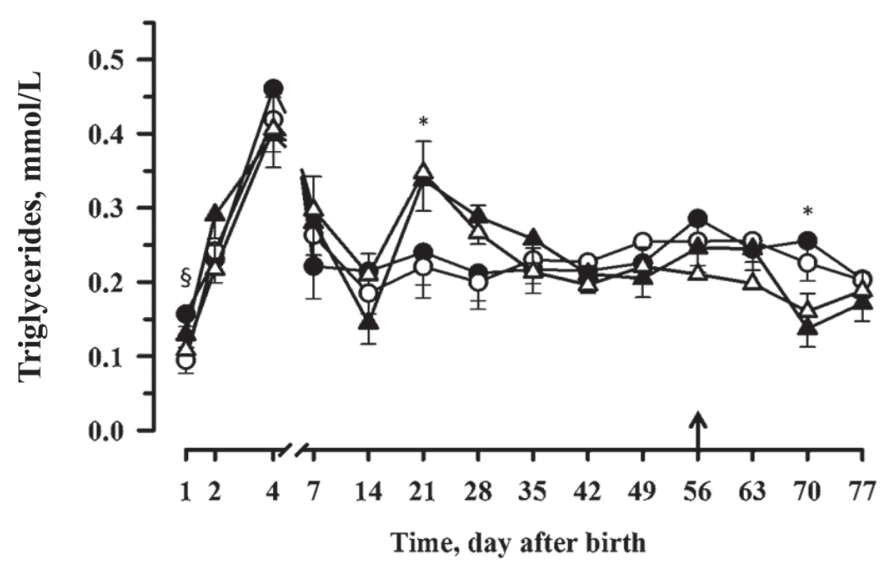

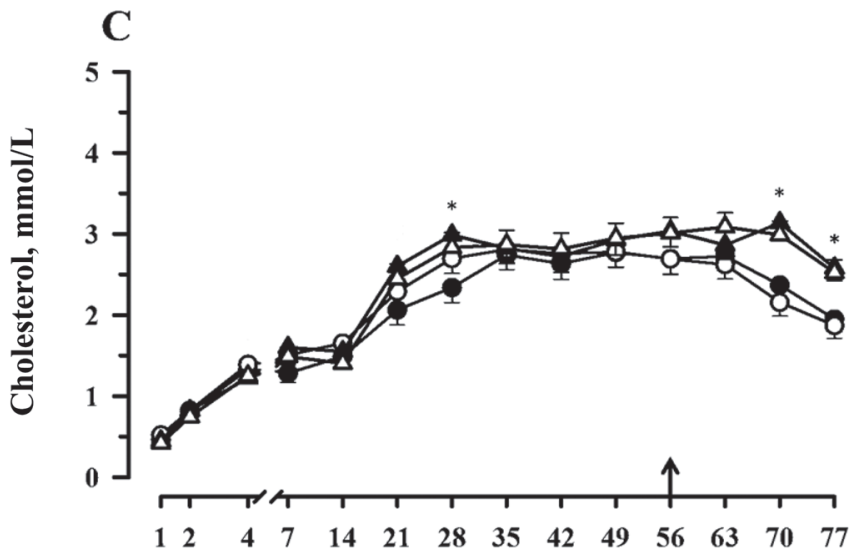

D

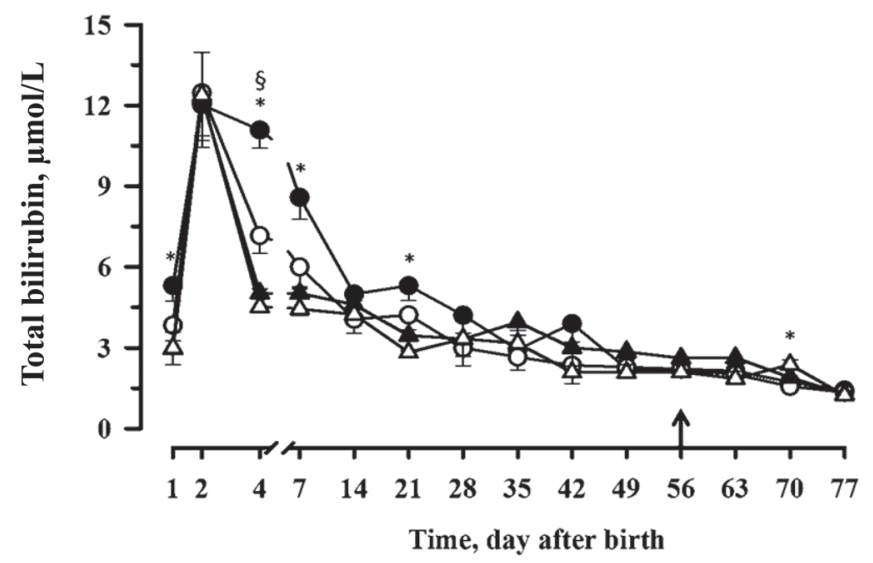

Figure 4. Blood plasma concentrations of nonesterified fatty acids (NEFA; A), triglycerides (B), cholesterol (C), and total bilirubin (D) in calves fed milk and milk replacer (MR) either ad libitum or restrictively and supplemented (MR) without $(\Delta$ AdlB - ; $\bigcirc$ ResB-) or with $0.24 \%$ butyrate $(\boldsymbol{A}$ AdlB + ; $\bullet$ ResB +$)$. Arrow marks the start of weaning. Data are presented as LSM \pm SE; * indicates the effect of feeding regimen $(P<0.05) ; \S$ indicates the effect of butyrate supplementation $(P<0.05)$. 




B
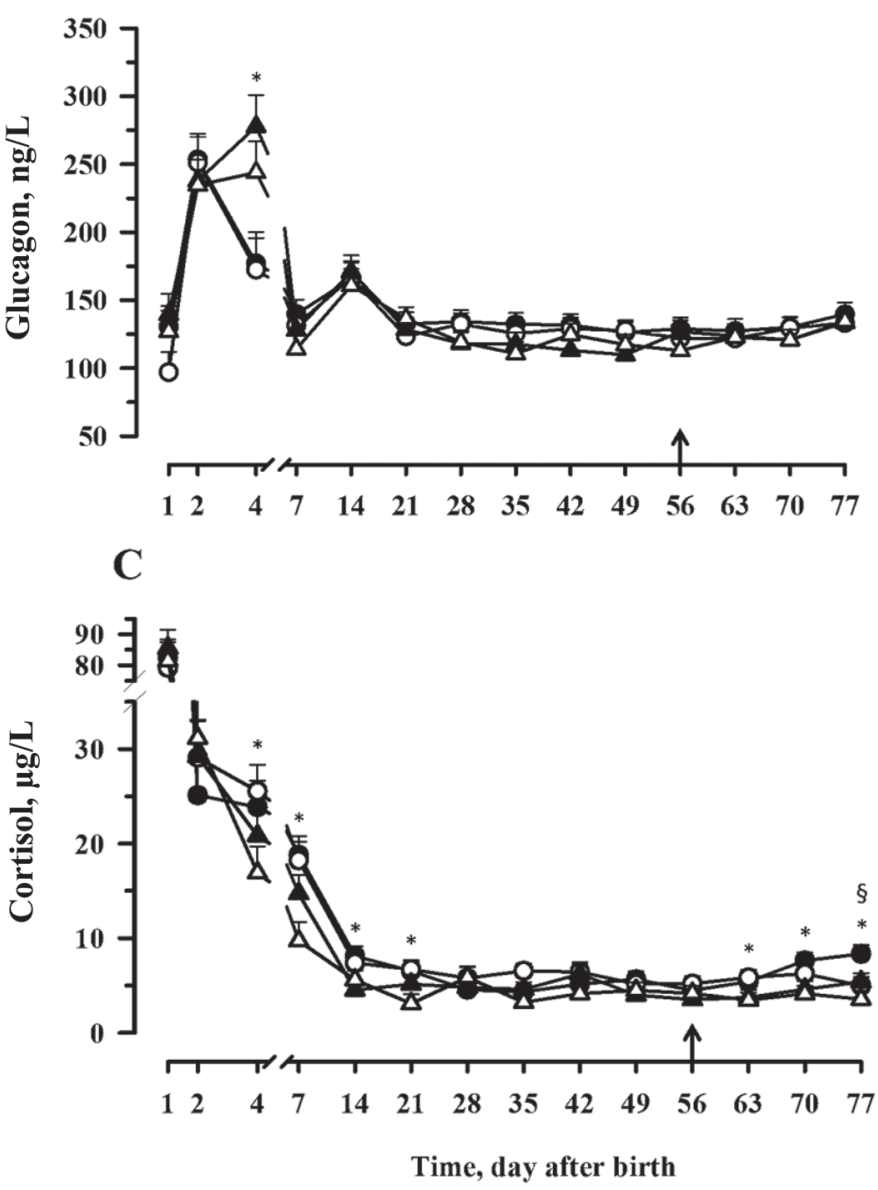

Figure 5. Blood plasma concentrations of insulin (A), glucagon (B), and cortisol (C) in calves fed milk and milk replacer (MR) either ad libitum or restrictively and supplemented MR without ( $\Delta$ AdlB-; $\bigcirc$ ResB - ) or with $0.24 \%$ butyrate $(\boldsymbol{\Delta}$ AdlB $+;-$ ResB + ). Arrow marks the start of weaning. Data are presented as $\mathrm{LSM} \pm \mathrm{SE}$; * indicates the effect of feeding regimen $(P<0.05) ; \S$ indicates the effect of butyrate supplementation $(P<0.05)$. among studies (Guilloteau et al., 2009, 2010; Górka et al., 2014), but butyrate content was lower than in cow milk (Chilliard et al., 2009). There might be differences in MR origin and calf management between the studies that lead to the divergent results. Butyrate fed to preweaning pigs stimulated growth and maturation of the small intestine enterocytes, which was barely observed in calves fed MR with butyrate (Guilloteau et al., 2010; Górka et al., 2014). Intestinal mucosa growth was stimulated by butyrate supplementation in the male calves of the current study [C. Gerbert, D. Frieten, C. Koch, G. Dusel, R. Zitnan (Research Centre Nitra, Kosice, Slovakia), H. M. Hammon, unpublished observation]. Surprisingly, the elevated mucosa growth due to butyrate treatment did not cause enhanced body growth or did not improve the gain to feed ratio.

Feed intake and growth performance was not affected by sex, although birth weight was numerically greater in male than female calves (data not shown). These findings are unexpected because birth weight and growth rates are typically greater in male than in female calves (Kerr et al., 1991; Kertz et al., 1997; Egli and Blum, 1998), but not all studies indicate sex differences in birth weight and growth performance in calves during the milk-fed period (Govoni et al., 2004; Schäff et al., 2016).

\section{Effects of Milk Feeding Intensity and Butyrate Supplementation on Systemic and Hepatic Metabolic Changes}

In the current study, ad libitum MR feeding primarily affected glucose metabolism. Plasma glucose usually decreases with age and increasing ruminant function (Quigley et al., 1991a,b; Hugi and Blum, 1997; Daniels et al., 2008). The decrease in plasma glucose with age was delayed in Adl calves compared with that of Res calves, and Adl calves showed a greater plasma glucose concentration during the intensive milk feeding period, which supports previous findings (Maccari et al., 2015; Schäff et al., 2016; Kesser et al., 2017). Elevated plasma glucose in Adl calves most likely resulted from increased glucose intake because no differences were observed in gene expression of gluconeogenic enzymes with respect to intensive MR feeding on d 50 of age. However, gene expression of gluconeogenic enzymes increased (with the exception of $P C$ ) with age in all calves, which fits the elevated ruminant function after increasing concentrate intake and elevated substrate supply for gluconeogenesis (Quigley et al., 1991b; Hammon et al., 2005; Kesser et al., 2017). However, the time pattern of gluconeogenic gene expression in growing calves is more variable and depends on the age of weaning and nutrient intake (Hammon et al., 
2005; Haga et al., 2008). The increased gene expression of gluconeogenic enzymes observed on d 80 was necessary to increase endogenous glucose production to maintain glucose homeostasis when oral glucose supply diminished. Indeed, hepatic glycogen concentration, which was elevated because of intensive MR feeding on d 50 of age, decreased in all calves on d 80. Hepatic gluconeogenic capacity was probably reduced in Adl calves at the end of the study because plasma glucose concentration was lower in Adl than in Res calves. The lower concentrate intake in Adl calves at the end of the study likely created less substrate for gluconeogenesis (Zhang et al., 2016).

The elevated plasma glucose concentration in ad libitum milk-fed calves caused an increase in plasma insulin during intensive milk feeding, as also indicated in previous studies (Daniels et al., 2008; Maccari et al., 2015; Schäff et al., 2016). Elevated insulin concentration in Adl calves was not a result of impaired insulin function (MacPherson et al., 2016; Kesser et al., 2017). The rise in plasma insulin might stimulate anabolic processes in muscle and fat tissue, leading to enhanced tissue growth in intensive milk-fed calves (Schäff et al., 2016). In contrast, plasma glucagon and cortisol decreased after the first week of life in all calves. The slower decrease of plasma cortisol during the first month of age in Res calves might indicate certain catabolic processes in these calves that were also observed in calves with impaired colostrum supply (Hammon and Blum, 1998; Kühne et al., 2000), and this observation fits with partly greater plasma NEFA and lactate concentrations in Res calves. The reasons for the higher plasma cortisol concentration at the end of the study in Res calves are currently not known and are inconsistent with the lower NEFA concentration in these calves. However, the cortisol concentration is low in general, and cortisol might be less metabolically effective during this time period. The rise in plasma glucagon during the first $24 \mathrm{~h}$ of age in all calves and the elevated glucagon concentration in Adl calves on d 4 mirror the high protein intake with colostrum feeding on $\mathrm{d} 1$ and the elevated protein intake owing to transition milk until d 4 in Adl calves (Hammon and Blum, 1998; Kühne et al., 2000). The elevated protein intake during the first days of age in Adl calves might also explain the increase in plasma urea concentration on $\mathrm{d}$ 4 of age (Rauprich et al., 2000). In addition, glucagon sensitivity decreases with age and rumen development (Donkin and Armentano, 1995; Baldwin et al., 2004), and the low plasma glucagon concentration after $3 \mathrm{wk}$ of age might be a component of the reduced glucagon action.

Table 3. Hepatic glycogen concentration and relative mRNA expression $\left(\log _{2}\right)$ of gluconeogenic enzymes on d 50 and 80 in calves fed milk and milk replacer (MR) either ad libitum or restrictively and supplemented MR without (ResB-; AdlB-) or with 0.24\% butyrate (ResB+; AdlB+)

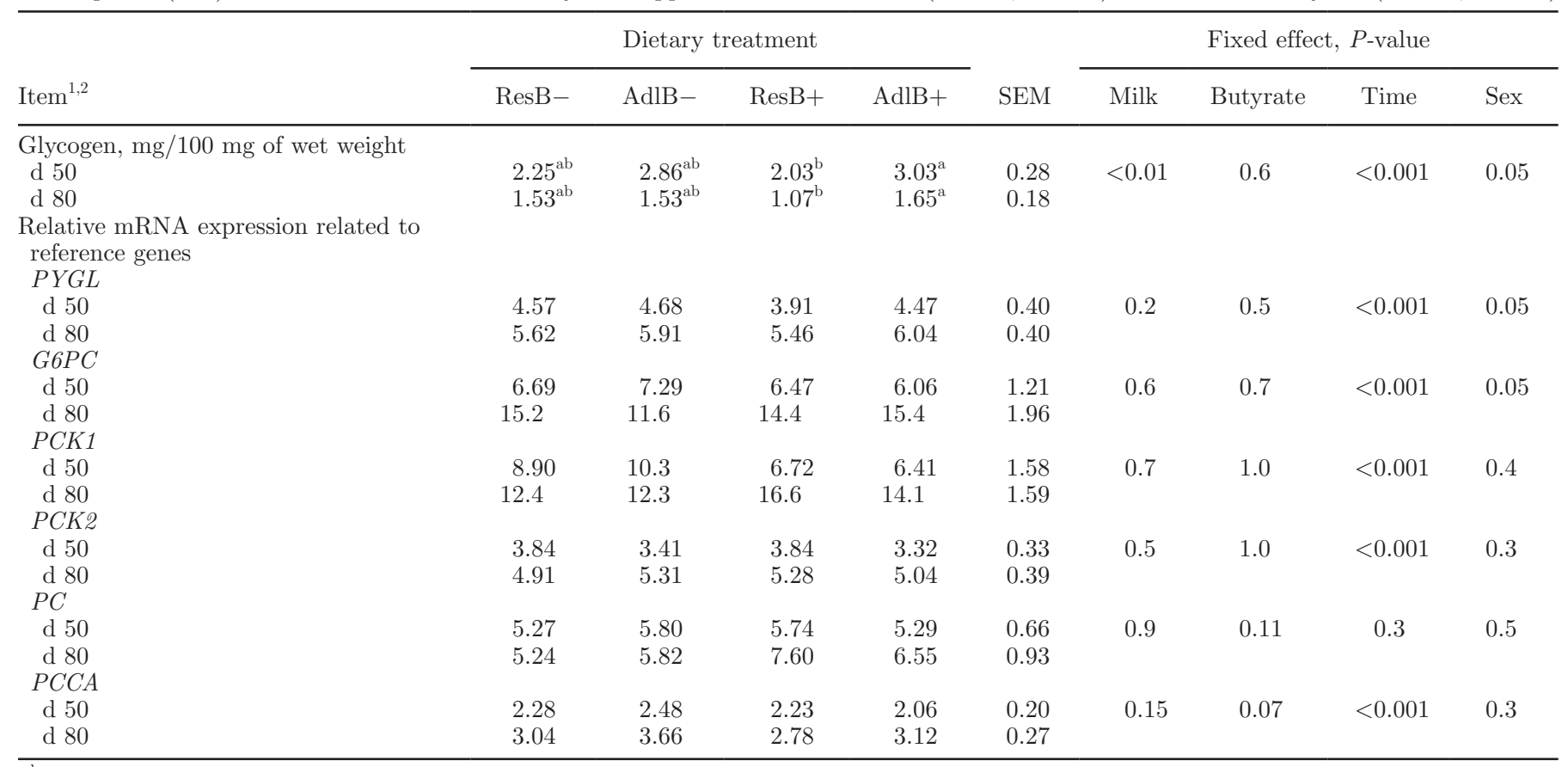

\footnotetext{
$\overline{\mathrm{a}, \mathrm{b}}$ Different letters within the same row indicate significant differences $(P \leq 0.05)$.

${ }^{1}$ Values are presented as LSM.

${ }^{2} P Y G L=$ glycogen phosphorylase; $G 6 P C=$ glucose-6-phosphatase; $P C K 1=$ phosphoenolpyruvate carboxykinase $($ cytosolic); $P C K 2=$ phosphoenolpyruvate carboxykinase (mitochondrial); $P C=$ pyruvate carboxylase; $P C C A=$ propionyl-CoA carboxylase $\alpha$.
} 
Owing to greater concentrate intake and rumen function, the increase in BHB plasma concentration occurred much earlier in Res than in Adl calves (Quigley et al., 1991b). Therefore, the BHB time pattern in blood plasma followed the concentrate intake, and in Adl calves, the increase in plasma BHB occurred only after the reduction of MR feeding and the increase in concentrate intake at the end of the study, which led to a comparable plasma BHB concentration between Adl and Res calves in wk 11 of age. This finding indicates that rumen functioning is quickly enhanced when MR intake decreases and concentrate intake increases. Supporting this assessment, papilla growth of the ruminal mucosa was measured in the male calves of this study and was not different between Res and Adl calves at d 80 of age [C. Gerbert, D. Frieten, C. Koch, G. Dusel, R. Zitnan (Research Centre Nitra, Kosice, Slovakia), and H. M. Hammon, unpublished observation].

Plasma triglycerides were enhanced only at d 21 during intensive milk feeding in Adl calves. This observation was in contrast to previous findings in which plasma triglycerides were elevated during the entire intensive milk-feeding period (Schäff et al., 2016). In wk 10, the reduced concentrate intake led to a lower plasma triglyceride concentration in Adl than in Res calves. The plasma cholesterol concentration increased with age, consistent with previous studies (Hammon et al., 2002; Maccari et al., 2015; Schäff et al., 2016), indicating an elevated concentration at certain time points because of intensive milk feeding, but was greater in Adl than in Res at the end of the study, when MR was low in all calves and concentrate intake was higher in Res calves. It is likely that the greater concentrate intake reduced cholesterol synthesis in the rumen epithelium and led to lower plasma cholesterol in Res calves (Steele et al., 2011). Plasma concentration of total bilirubin increases after birth in neonates as a consequence of destruction of fetal hemoglobin in the liver and spleen (Egli and Blum, 1998; Chowdhury and Chowdhury, 2009). The elevated plasma total bilirubin during the first week of age in Res calves might be a consequence of increased plasma NEFA in these calves. Plasma NEFA likely competes with plasma albumin binding and might affect hepatic bilirubin metabolism (Hadorn et al., 1997; Chowdhury and Chowdhury, 2009).

Overall, butyrate insignificantly affected metabolic and endocrine changes in calves in the current study. As mentioned previously, butyrate was not detected in blood plasma of calves fed MR with butyrate, which was also the case in previous studies (Guilloteau et al., 2010). An elevated plasma glucose concentration owing to butyrate feeding by MR (as reported by Górka et al., 2011) or enhanced insulin sensitivity (as stated by Kato et al., 2011) could not be supported herein.
The opposite was the case because plasma glucose was lower at certain time points in calves fed MR with butyrate. Minor effects of oral butyrate supplementation were noted in the liver on gene expression of $P C$ and $P C C A$. However, these data are difficult to interpret because hepatic PCCA mRNA was reduced and $P C$ mRNA was slightly increased by butyrate treatment, but no differences in feed intake were observed because of butyrate supplementation, assuming the same gluconeogenic substrate supply in calves fed butyrate or not. Therefore, depressed plasma glucose because of butyrate feeding might result from impaired glucose uptake, but less is known as to whether butyrate affects lactose digestion and glucose absorption in pre-weaning calves.

Although growth performance was not affected by sex, female calves indicated greater plasma glucose, insulin, and glucagon concentrations and had a greater hepatic glycogen concentration than male calves. Sex effects on glucose metabolism in neonatal calves were also reported in previous studies (Sasaki et al., 2002; Schäff et al., 2016; Kesser et al., 2017). Interestingly, gene expression of $P Y G L$ and $G 6 P C$ was greater in male than female calves. Obviously, greater endocrine glucose production occurs in male than in female calves, which compensates for the lower glucose status in male calves. However, further studies are needed to comprehend the sex differences in glucose metabolism in pre-weaning calves.

\section{CONCLUSIONS}

Ad libitum MR feeding for 8 wk resulted in elevated nutrient intake and accelerated growth but did not improve the feed conversion ratio. The metabolic and endocrine status mirrored the stimulation of anabolic processes to support body growth. Surprisingly and contrary to our hypothesis, the combination of an intensive milk-feeding program and allocation of butyrate with the MR did not result in an improvement in body growth beyond the growth stimulation owing to ad libitum MR feeding. In our study, butyrate was not able to provide additional stimulation on body growth, either in the ad libitum or in the restrictive MR feeding groups.

\section{ACKNOWLEDGMENTS}

The authors are grateful to C. Reiko, U. Wiedemuth, and P. Müntzel [Leibniz Institute for Farm Animal Biology (FBN), Dummerstorf, Germany] for excellent laboratory work and thank the staff of the Educational and Research Centre for Animal Husbandry, Hofgut Neumuehle, and the Animal Nutrition team and students at the University of Applied Sciences Bingen. 


\section{REFERENCES}

Bach, A. 2012. Ruminant Nutrition Symposium: Optimizing performance of the offspring: Nourishing and managing the dam and postnatal calf for optimal lactation, reproduction, and immunity. J. Anim. Sci. 90:1835-1845. https://doi.org/10.2527/jas.20114516.

Baldwin, R. L., K. R. McLeod, J. L. Klotz, and R. N. Heitmann. 2004 Rumen development, intestinal growth and hepatic metabolism in the pre- and postweaning ruminant. J. Dairy Sci. 87:E55-E65. https://doi.org/10.3168/jds.S0022-0302(04)70061-2.

Bar-Peled, U., B. Robinzon, E. Maltz, H. Tagari, Y. Folman, I. Bruckental, H. Voet, H. Gacitua, and A. R. Lehrer. 1997. Increased weight gain and effects on production parameters of Holstein heifer calves that were allowed to suckle from birth to six weeks of age. J. Dairy Sci. 80:2523-2528. https://doi.org/10.3168/jds.S00220302(97)76205-2.

Bartlett, K. S., F. K. McKeith, M. J. VandeHaar, G. E. Dahl, and J. K. Drackley. 2006. Growth and body composition of dairy calves fed milk replacers containing different amounts of protein at two feeding rates. J. Anim. Sci. 84:1454-1467.

Brown, E. G., M. J. VandeHaar, K. M. Daniels, J. S. Liesman, L. T. Chapin, D. H. Keisler, and M. S. Weber Nielsen. 2005. Effect of increasing energy and protein intake on body growth and carcass composition of heifer calves. J. Dairy Sci. 88:585-594. https://doi. org/10.3168/jds.S0022-0302(05)72722-3.

Chilliard, Y., C. Martin, J. Rouel, and M. Doreau. 2009. Milk fatty acids in dairy cows fed whole crude linseed, extruded linseed, or linseed oil, and their relationship with methane output. J. Dairy Sci. 92:5199-5211. https://doi.org/10.3168/jds.2009-2375.

Chowdhury, N. R., and J. R. Chowdhury. 2009. Disorders of bilirubin metabolism. Pages 251-256 in The Liver: Biology and Pathobiology. I. M. Arias, H. J. Alter, J. L. Boyer, D. E. Cohen, N. Fausto, D. A. Shafritz, and A. W. Wolkoff, ed. John Wiley \& Sons, West Sussex, UK. https://doi.org/10.1002/9780470747919.ch17.

Daniels, K. M., A. V. Capuco, M. L. McGilliard, R. E. James, and R. M. Akers. 2009. Effects of milk replacer formulation on measures of mammary growth and composition in Holstein heifers. J. Dairy Sci. 92:5937-5950. https://doi.org/10.3168/jds.2008-1959.

Daniels, K. M., S. R. Hill, K. F. Knowlton, R. E. James, M. L. McGilliard, and R. M. Akers. 2008. Effects of milk replacer composition on selected blood metabolites and hormones in preweaned Holstein heifers. J. Dairy Sci. 91:2628-2640. https://doi.org/10.3168/ jds.2007-0859.

Davis Rincker, L. E., M. J. VandeHaar, C. A. Wolf, J. S. Liesman, L. T. Chapin, and M. S. Weber Nielsen. 2011. Effect of intensified feeding of heifer calves on growth, pubertal age, calving age, milk yield, and economics. J. Dairy Sci. 94:3554-3567. https://doi. org/10.3168/jds.2010-3923.

de Passillé, A. M., M. Rabeyrin, and J. Rushen. 2016. Associations between milk intake and activity in the first days of a calf's life and later growth and health. Appl. Anim. Behav. Sci. 175:2-7. https:// doi.org/10.1016/j.applanim.2014.10.002.

Donkin, S. S., and L. E. Armentano. 1995. Insulin and glucagon regulation of gluconeogenesis in preruminating and ruminating bovine. J. Anim. Sci. 73:546-551.

Egli, C. P., and J. W. Blum. 1998. Clinical, haematological, metabolic and endocrine traits during the first three months of life of suckling simmentaler calves held in a cow-calf operation. Zentralbl. Veterinarmed. A 45:99-118.

Geiger, A. J., C. L. M. Parsons, R. E. James, and R. M. Akers. 2016. Growth, intake, and health of Holstein heifer calves fed an enhanced preweaning diet with or without postweaning exogenous estrogen. J. Dairy Sci. 99:3995-4004. https://doi.org/10.3168/ jds.2015-10405.

GfE. 2009. New equations for predicting metabolisable energy of compound feeds for cattle. Proc. Soc. Nutr. Physiol. 18:143-146.

Górka, P., Z. M. Kowalski, P. Pietrzak, A. Kotunia, W. Jagusiak, J. J. Holst, P. Guilloteau, and R. Zabielski. 2011. Effect of method of delivery of sodium butyrate on rumen development in new- born calves. J. Dairy Sci. 94:5578-5588. https://doi.org/10.3168/ jds.2011-4166.

Górka, P., P. Pietrzak, A. Kotunia, R. Zabielski, and Z. M. Kowalski. 2014. Effect of method of delivery of sodium butyrate on maturation of the small intestine in newborn calves. J. Dairy Sci. 97:1026-1035. https://doi.org/10.3168/jds.2013-7251.

Govoni, K. E., T. A. Hoagland, and S. A. Zinn. 2004. The ontogeny of the somatotropic axis in Hereford calves from birth to one year of age and its response to administration of exogenous bovine somatotropin. J. Anim. Sci. 82:1646-1655.

Gross, J. J., E. C. Kessler, and R. M. Bruckmaier. 2016. Estimation of quarter vs. composite colostrum composition via Brix refractometry, specific gravity, and visual color appearance in dairy cows. J. Anim. Sci. 94:399. https://doi.org/10.2527/jam2016-0846.

Gruse, J., S. Görs, A. Tuchscherer, W. Otten, J. M. Weitzel, C. C. Metges, S. Wolffram, and H. M. Hammon. 2015. The effects of oral quercetin supplementation on splanchnic glucose metabolism in 1-week-old calves depend on diet after birth. J. Nutr. 145:24862495. https://doi.org/10.3945/jn.115.218271.

Gruse, J., E. Kanitz, J. M. Weitzel, A. Tuchscherer, T. Stefaniak, P. Jawor, S. Wolffram, and H. M. Hammon. 2016. Quercetin feeding in newborn dairy calves cannot compensate colostrum deprivation: Study on metabolic, antioxidative and inflammatory traits. PLoS One 11:e0146932 https://doi.org/10.1371/journal.pone.0146932.

Guilloteau, P., L. Martin, V. Eeckhaut, R. Ducatelle, R. Zabielski, and F. Van Immerseel. 2010. From the gut to the peripheral tissues: The multiple effects of butyrate. Nutr. Res. Rev. 23:366-384. https://doi.org/10.1017/S0954422410000247.

Guilloteau, P., R. Zabielski, J. C. David, J. W. Blum, J. A. Morisset, M. Biernat, J. Woliński, D. Laubitz, and Y. Hamon. 2009. Sodium-butyrate as a growth promoter in milk replacer formula for young calves. J. Dairy Sci. 92:1038-1049. https://doi.org/10.3168/ jds.2008-1213.

Hadorn, U., H. Hammon, R. M. Bruckmaier, and J. W. Blum. 1997. Delaying colostrum intake by one day has important effects on metabolic traits and on gastrointestinal and metabolic hormones in neonatal calves. J. Nutr. 127:2011-2023.

Haga, S., S. Fujimoto, T. Yonezawa, K. Yoshioka, H. Shingu, Y. Kobayashi, T. Takahashi, Y. Otani, K. Katoh, and Y. Obara. 2008. Changes in hepatic key enzymes of dairy calves in early weaning production systems. J. Dairy Sci. 91:3156-3164. https://doi. org/10.3168/jds.2007-0853.

Hammon, H. M., and J. W. Blum. 1998. Metabolic and endocrine traits of neonatal calves are influenced by feeding colostrum for different durations or only milk replacer. J. Nutr. 128:624-632.

Hammon, H. M., C. Philipona, Y. Zbinden, J. W. Blum, and S. S. Donkin. 2005. Effects of dexamethasone and growth hormone treatment on hepatic gluconeogenic enzymes in calves. J. Dairy Sci. 88:2107-2116.

Hammon, H. M., G. Schiessler, A. Nussbaum, and J. W. Blum. 2002 Feed intake patterns, growth performance, and metabolic and endocrine traits in calves fed unlimited amounts of colostrum and milk by automate, starting in the neonatal period. J. Dairy Sci. 85:3352-3362

Hammon, H. M., G. Stürmer, F. Schneider, A. Tuchscherer, H. Blum, T. Engelhard, A. Genzel, R. Staufenbiel, and W. Kanitz. 2009 Performance and metabolic and endocrine changes with emphasis on glucose metabolism in high-yielding dairy cows with high and low fat content in liver after calving. J. Dairy Sci. 92:1554-1566. https://doi.org/10.3168/jds.2008-1634.

Hill, T. M., J. D. Quigley, H. G. Bateman, F. X. Suarez-Mena, T. S. Dennis, and R. L. Schlotterbeck. 2016. Effect of milk replacer program on calf performance and digestion of nutrients in dairy calves to 4 months of age. J. Dairy Sci. 99:8103-8110. https://doi org/10.3168/jds.2016-11239.

Hugi, D., and J. W. Blum. 1997. Changes of blood metabolites and hormones in breeding calves associated with weaning. Zentralbl. Veterinarmed. A 44:99-108.

Jasper, J., and D. M. Weary. 2002. Effects of ad libitum milk intake on dairy calves. J. Dairy Sci. 85:3054-3058. https://doi.org/10.3168/ jds.S0022-0302(02)74391-9. 
Kato, S., K. Sato, H. Chida, S.-G. Roh, S. Ohwada, S. Sato, P. Guilloteau, and K. Katoh. 2011. Effects of Na-butyrate supplementation in milk formula on plasma concentrations of GH and insulin, and on rumen papilla development in calves. J. Endocrinol. 211:241248. https://doi.org/10.1530/JOE-11-0299.

Kerr, D. E., B. Laarveld, M. I. Fehr, and J. G. Manns. 1991. Profiles of serum IGF-I concentrations in calves from birth to eighteen months of age and in cows throughout the lactation cycle. Can. J. Anim. Sci. 71:695-705. https://doi.org/10.4141/cjas91-085.

Kertz, A. F., L. F. Reutzel, B. A. Barton, and R. L. Ely. 1997. Body weight, body condition score, and wither height of prepartum Holstein cows and birth weight and sex of calves by parity: a database and summary. J. Dairy Sci. 80:525-529. https://doi.org/10.3168/ jds.S0022-0302(97)75966-6

Kesser, J., M. Korst, C. Koch, F.-J. Romberg, J. Rehage, U. Müller, M. Schmicke, K. Eder, H. M. Hammon, H. Sadri, and H. Sauerwein. 2017. Different milk feeding intensities during the first four weeks of rearing dairy calves: Part 2: Effects on the metabolic and endocrine status during calfhood and around the first lactation. J. Dairy Sci. 100:3109-3125. https://doi.org/10.3168/jds.2016-11595.

Khan, M. A., A. Bach, D. M. Weary, and M. A. G. von Keyserlingk. 2016. Invited review: Transitioning from milk to solid feed in dairy heifers. J. Dairy Sci. 99:885-902. https://doi.org/10.3168/ jds.2015-9975.

Khan, M. A., H. J. Lee, W. S. Lee, H. S. Kim, S. B. Kim, K. S. Ki, J. K. Ha, H. G. Lee, and Y. J. Choi. 2007. Pre- and postweaning performance of Holstein female calves fed milk through step-down and conventional methods. J. Dairy Sci. 90:876-885. https://doi. org/10.3168/jds.S0022-0302(07)71571-0.

Khan, M. A., D. M. Weary, and M. A. G. von Keyserlingk. 2011. Invited review: Effects of milk ration on solid feed intake, weaning, and performance in dairy heifers. J. Dairy Sci. 94:1071-1081. https://doi.org/10.3168/jds.2010-3733.

Korst, M., C. Koch, J. Kesser, U. Müller, F.-J. Romberg, J. Rehage, K. Eder, and H. Sauerwein. 2017. Different feeding intensities during the first four weeks of rearing in dairy calves: Part 1: Effects on performance and production from birth over the first lactation. J. Dairy Sci. https://doi.org/10.3168/jds.2016-11594.

Kühne, S., H. M. Hammon, R. M. Bruckmaier, C. Morel, Y. Zbinden, and J. W. Blum. 2000. Growth performance, metabolic and endocrine traits, and absorptive capacity in neonatal calves fed either colostrum or milk replacer at two levels. J. Anim. Sci. 78:609-620.

Laeger, T., S. Görs, C. C. Metges, and B. Kuhla. 2012. Effect of feed restriction on metabolites in cerebrospinal fluid and plasma of dairy cows. J. Dairy Sci. 95:1198-1208. https://doi.org/10.3168/ jds.2011-4506.

Maccari, P., S. Wiedemann, H.-J. Kunz, M. Piechotta, P. Sanftleben, and M. Kaske. 2015. Effects of two different rearing protocols for Holstein bull calves in the first 3 weeks of life on health status, metabolism and subsequent performance. J. Anim. Physiol. Anim. Nutr. (Berl.) 99:737-746. https://doi.org/10.1111/jpn.12241.

MacPherson, J. A. R., H. Berends, L. N. Leal, J. P. Cant, J. MartinTereso, and M. A. Steele. 2016. Effect of plane of milk replacer intake and age on glucose and insulin kinetics and abomasal emptying in female Holstein Friesian dairy calves fed twice daily. J. Dairy Sci. 99:8007-8017. https://doi.org/10.3168/jds.2015-10826.

Miller-Cushon, E. K., R. Bergeron, K. E. Leslie, and T. J. DeVries. 2013. Effect of milk feeding level on development of feeding behavior in dairy calves. J. Dairy Sci. 96:551-564. https://doi. org /10.3168/jds.2012-5937.

Naumann, C., and R. Bassler. 2004. Die chemische Untersuchung von Futtermittel. VDLUFA-Verlag, Darmstadt, Germany.
NRC. 2001. Nutrient Requirements of Dairy Cattle. 7th rev. ed. Natl. Acad. Press, Washington, D.C.

Ollivett, T. L., D. V. Nydam, T. C. Linden, D. D. Bowman, and M. E. Van Amburgh. 2012. Effect of nutritional plane on health and performance in dairy calves after experimental infection with Cryptosporidium parvum. J. Am. Vet. Med. Assoc. 241:1514-1520.

Quigley, J. D., 3rd, L. A. Caldwell, G. D. Sinks, and R. N. Heitmann. 1991a. Changes in blood glucose, nonesterified fatty acids, and ketones in response to weaning and feed intake in young calves. J. Dairy Sci. 74:250-257. https://doi.org/10.3168/jds.S00220302(91)78167-8

Quigley, J. D., 3rd, Z. P. Smith, and R. N. Heitmann. 1991b. Changes in plasma volatile fatty acids in response to weaning and feed intake in young calves. J. Dairy Sci. 74:258-263. https://doi. org/10.3168/jds.S0022-0302(91)78168-X .

Rauprich, A. B. E., H. M. Hammon, and J. W. Blum. 2000. Influence of feeding different amounts of first colostrum on metabolic, endocrine, and health status and on growth performance in neonatal calves. J. Anim. Sci. 78:896-908.

Ruijter, J. M., M. W. Pfaffl, S. Zhao, A. N. Spiess, G. Boggy, J. Blom, R. G. Rutledge, D. Sisti, A. Lievens, K. De Preter, S. Derveaux, J. Hellemans, and J. Vandesompele. 2013. Evaluation of qPCR curve analysis methods for reliable biomarker discovery: Bias, resolution, precision, and implications. Methods 59:32-46. https://doi. org/10.1016/j.ymeth.2012.08.011.

Saremi, B., H. Sauerwein, S. Dänicke, and M. Mielenz. 2012. Technical note: Identification of reference genes for gene expression studies in different bovine tissues focusing on different fat depots. J. Dairy Sci. 95:3131-3138. https://doi.org/10.3168/jds.2011-4803.

Sasaki, O., N. Yamamoto, K. Togashi, and M. Minezawa. 2002. Effects of age, environments and sex on plasma metabolite levels in young Holstein calves. Asian-australas. J. Anim. Sci. 15:637-642. https://doi.org/10.5713/ajas.2002.637.

Schäff, C. T., J. Gruse, J. Maciej, M. Mielenz, E. Wirthgen, A. Hoeflich, M. Schmicke, R. Pfuhl, P. Jawor, T. Stefaniak, and H. M. Hammon. 2016. Effects of feeding milk replacer ad libitum or in restricted amounts for the first five weeks of life on the growth, metabolic adaptation, and immune status of newborn calves. PLoS One 11:e0168974. https://doi.org/10.1371/journal.pone.0168974.

Schiessler, G., A. Nussbaum, H. M. Hammon, and J. W. Blum. 2002 Calves sucking, colostrum and milk from their dams or from an automatic feeding station starting in the neonatal period: Metabolic and endocrine traits and growth performance. Anim. Sci. 74:431-444. https://doi.org/10.1017/S1357729800052589.

Steele, M. A., G. Vandervoort, O. AlZahal, S. E. Hook, J. C. Matthews, and B. W. McBride. 2011. Rumen epithelial adaptation to high-grain diets involves the coordinated regulation of genes involved in cholesterol homeostasis. Physiol. Genomics 43:308-316. https://doi.org/10.1152/physiolgenomics.00117.2010.

Swanson, K. S., N. R. Merchen, J. W. Erdman Jr., J. K. Drackley, F. Orias, G. N. Douglas, and J. C. Huhn. 2000. Technical note: A technique for multiple liver biopsies in neonatal calves. J. Anim. Sci. 78:2459-2463.

Van Amburgh, M. E., and F. Soberon. 2013. The role of calf nutrition and management on lifetime productivity of dairy cattle. Pages 178-197 in Cow Longevity Conference, Hamra Farm, Tumba, Sweden.

Zhang, Q., S. L. Koser, and S. S. Donkin. 2016. Propionate induces mRNA expression of gluconeogenic genes in bovine calf hepatocytes. J. Dairy Sci. 99:3908-3915. https://doi.org/10.3168/ jds.2015-10312. 